\title{
Echocardiographic Evaluation of the Effect of Poor Blood Glucose Control on Left Ventricular Function and Ascending Aorta Elasticity
}

\section{Xiang-Ting Song}

Changzhou NO.2 People's Hospital Affiliated to Nanjing Medical University

\section{Li Fan}

Changzhou NO.2 People's Hospital Affiliated to Nanjing Medical University

\section{Zi-Ning Yan (D 531351268@qq.com )}

Changzhou NO.2 People's Hospital Affiliated to Nanjing Medical University https://orcid.org/00000003-1450-734X

\section{Yi-Fei Rui}

Changzhou NO.2 People's Hospital Affiliated to Nanjing Medical University

\section{Original investigation}

Keywords: Type 2 diabetes mellitus, Echocardiography, Left ventricular, Systolic function, Diastolic function, Ascending aorta, Elasticity

Posted Date: December 4th, 2020

DOl: https://doi.org/10.21203/rs.3.rs-117824/v1

License: (1) This work is licensed under a Creative Commons Attribution 4.0 International License. Read Full License 


\title{
Echocardiographic evaluation of the effect of poor blood glucose control on left ventricular function and ascending aorta elasticity
}

Xiang-Ting Song, Li Fan, Zi-Ning Yan, Yi-Fei Rui

Department of Echocardiography, Changzhou No.2 People's Hospital Affiliated to Nanjing Medical University, Changzhou, 213003, China

Corresponding Author:

Zi-Ning Yan, Department of Echocardiography, Changzhou No. 2 People's Hospital Affiliated to Nanjing Medical University, Changzhou, 213003, China

E-mail: 531351268@qq.com

\begin{abstract}
Background: Type 2 diabetes mellitus (T2DM) is associated with high cardiovascular risk. Preclinical left ventricular (LV) dysfunction and subclinical arterial stiffness have been documented in patients with T2DM. The aims of this study were to investigate whether there was any differences in LV function and ascending aorta elasticity between T2DM patients with controlled [defined as glycosylated hemoglobin $\left(\mathrm{HbA}_{1 c}\right)<6.5 \%$ ] and uncontrolled $\left(\mathrm{HbA}_{1 \mathrm{c}} \geq 6.5 \%\right)$ blood glucose.
\end{abstract}

Methods: We studied 86 T2DM patients with preserved LV ejection fraction (LVEF) whom be divided into two groups: 42 T2DM patients with controlled blood glucose (controlled T2DM group) and 44 T2DM patients with uncontrolled blood glucose (uncontrolled T2DM group), and 40 ageand gender-matched healthy subjects as controls. They all underwent transthoracic echocardiography examination, LV systolic function was evaluated by global longitudinal strain (GLS) measured using three-dimensional speckle-tracking echocardiography. LV diastolic function was defined as the ratio of the early diastolic transmitral flow velocities (E) to average mitral annular velocity $(\overline{\mathrm{e}})$, and $\mathrm{E} / \overline{\mathrm{e}}>14$ was determined as abnormal. Ascending aorta inner diameters and brachial blood pressure were measured to calculate ascending aorta elastic parameters: compliance (C), distensibility (D), strain (S), stiffness index (SI), Peterson's elastic modulus (EM).

Results: Compared to controls, patients with T2DM had reduced GLS, increased E/ $\overline{\mathrm{e}}$ and impaired ascending aorta elasticity. Furthermore, LV function and ascending aorta elasticity were more severely damaged in uncontrolled T2DM group compared with controlled T2DM group. By Pearson correlation analysis, the level of $\mathrm{HbA}_{1 \mathrm{c}}$ was independently associated with the parameters of the LV function and ascending aorta elasticity.

Conclusions: T2DM can impair LV myocardial function and ascending aorta elastic properties. Poor blood glucose control can lead to further damage to LV function and elasticity of the ascending aorta.

Keywords: Type 2 diabetes mellitus, Echocardiography, Left ventricular, Systolic function, Diastolic function, Ascending aorta, Elasticity

\section{Background}

Type 2 diabetes mellitus (T2DM) is one of the most common metabolic diseases worldwide with 
continuously increasing prevalence [1]. It is associated with increased risk for cardiovascular systems among patients with T2DM [2]. Bhatt et al.[3] showed that the prevalence and mortality of cardiovascular events in diabetic patients are 2 to 4 times that of non-diabetic patients, and become the leading cause of death in diabetic patients. A major cause of increased mortality in T2DM patients is diabetic cardiomyopathy (DCM), which is defined as myocardial dysfunction that is independent of coronary artery disease and hypertension and can lead to heart failure in diabetic patients [3-6]. Arterial stiffness is also closely related to diabetes, especially the elasticity of ascending aorta, is an important predictor of the incidence and death of various diseases. Studies have confirmed that there is damage to LV function and ascending aorta elasticity in patients with T2DM [7-9]. However, there is a paucity of research in the literature regarding whether there are any differences in LV function and ascending aorta elasticity between T2DM patients with controlled and uncontrolled blood glucose. Therefore, this study aims at evaluating the changes of LV function and ascending aorta elasticity in T2DM patients with controlled and uncontrolled blood glucose, and their correlation with $\mathrm{HbA}_{1 \mathrm{c}}$.

\section{Materials and Methods}

\section{Study Population}

The study group consisted of 86 T2DM patients who were admitted to our endocrinology inpatient wards between July 2017 and October 2020 and 40 healthy controls. The diagnosis of T2DM was made according to the 2010 guidelines of the American Diabetes Association [10]. All T2DM patients were divided into two groups according to the level of $\mathrm{HbA}_{1 c}$ : controlled T2DM group $\left(\mathrm{HbA}_{1 \mathrm{c}}<6.5 \%, \mathrm{n}=42\right)$ and uncontrolled T2DM group $\left(\mathrm{HbA}_{1 \mathrm{c}} \geq 6.5 \%, \mathrm{n}=44\right)$. Exclusion criteria for this study were as follows: type 1 diabetes mellitus, medical history of T2DM for $>10$ years, preexisting aortic disease, LVEF $<50 \%$, coronary heart disease, hypertension, congenital heart disease, cardiomyopathy, valvular heart disease, cerebrovascular disease, severe arrhythmia and acute complications of diabetes.

40 age- and gender-matched healthy subjects were recruited from individuals who presented for routine checkups at our hospital as control group if they met the following criteria: no evidence of abnormal glucose metabolism and preexisting aortic disease; electrocardiogram, echocardiogram and $\mathrm{X}$-ray examinations were all normal.

\section{General clinical and Biochemical Parameters}

Detailed medical history and thorough physical examination of all the participants were conducted. Height and weight were obtained and body mass index (BMI) was calculated as weight (in kilograms) divided by the square of height (in meters).

For blood pressure measurement, prior to echocardiography examination, all participants were lying in supine position for 10 minutes at rest, then right brachial systolic blood pressure (SBP) and diastolic blood pressure (DBP) were measured twice using a mercury sphygmomanometer in the morning between 8 and $10 \mathrm{am}$, with the mean value recorded. The interval between the two measurements was $>5$ minutes. Pulse pressure (PP) was calculated as SBP - DBP.

Venous blood samples were collected from all participants after 12 hours of fasting. The levels of total cholesterol (TCH), triglycerides (TG), high-density lipoprotein cholesterol (HDL-C) and low-density lipoprotein cholesterol (LDL-C) were measured using standard laboratory techniques in all participants. For T2DM patients, their fasting plasma glucose (FPG) and $\mathrm{HbA}_{1 c}$ were 
measured at the same time.

\section{Echocardiographic Examination}

Transthoracic echocardiography examination was performed using Philips IE33 echocardiography machine (Philips Medical Systems, Bothell, Washington, United States of America) in all participants by an experienced cardiologist. All participants were examined in the left lateral decubitus position, and left atrial diameter (LAD), diameter of interventricular septum (IVSD) and left ventricular posterior wall (LVPWD) in end-diastolic period, left ventricular end-systolic diameter (LVESD) and left ventricular end-diastolic diameter (LVEDD) were measured by M-mode echocardiography in the parasternal long-axis view.

For the assessment of LV systolic function, LVEF was calculated from M-mode echocardiographic tracings using parasternal long-axis view of the LV. Real-time three-dimensional echocardiography (RT3DE) was performed from the apical position using a commercial scanner (1.6-3.2 MHz, X5-1, Philips iE33; Philips Medical, Best, Netherlands). Adjust the machine in two-dimensional mode to clearly display the endocardium, then start full volume imaging, dynamic images of 3 consecutive cardiac cycles were collected when participants hold their breath. Electrocardiogram leads were connected to each individual during the entire echocardiography session. All echocardiographic images were analyzed offline by TomTec Image-Arena 4.6 workstation. After the LV long axis was manually aligned in three apical views (four-, three-, and two-chamber), the software automatically identified the LV endocardial border and tracked it throughout the cardiac cycle. The endocardial border and myocardial thickness could be manually adjusted after automatic detection if necessary. Then, the system automatically performed segmental strain analysis through an entire cardiac cycle and provided continuous values of global and segmental strain. In this study, we only selected global longitudinal strain (GLS) to evaluate the LV systolic function, due to it is a sensitive indicator of early LV systolic dysfunction [11].

To assess LV diastolic function, early $(E)$ and late $(A)$ transmitral flow velocities were measured in the four-chamber view using pulsed-wave Doppler with the sample volume placed between the tips of the mitral leaflets, and the ratio of early-to-late peak velocities $(E / A)$ were obtained [12]. Early diastolic myocardial velocity $(\overline{\mathrm{e}})$ was obtained by averaging the septal and lateral mitral annulus. Diastolic dysfunction cut-off was set to $E / \overline{\mathrm{e}}>14$ as recommended by the ASE/EACVI [13].

\section{Ascending Aorta Elasticity Assessment}

The diameters of the ascending aorta were measured in the parasternal long-axis view using $\mathrm{M}$-mode tracing at 4 levels at the end of diastole: sinus of valsalva (SV, maximum diameter of valsalva sinus), sinotubular junction (STJ), tubular tract (TT, proximal ascending aorta inner diameter $2 \mathrm{~cm}$ above the sinotubular junction) and aortic arch (AoAr, between innominate artery and left common carotid artery). To calculate ascending aorta elasticity parameters, an $\mathrm{M}$ - mode of ascending aorta was obtained above $3 \mathrm{~cm}$ from the aortic annulus [14]. The ascending aorta diastolic diameter (AADD) was measured th the peak of the QRS complex on the simultaneously recorded electrocardiogram, whereas the ascending aorta systolic diameter (AASD) was measured during the maximum anterior motion of the aorta (Fig. 1) [15]. The elastic parameters of the ascending aorta: C, D, S, SI and EM were calculated according to the below formulas [16, 
17].

Compliance $(C)=10 \times\left(\right.$ AASD - AADD) $/($ SBP-DBP $)\left(10^{-1} \mathrm{~mm} / \mathrm{mmHg}\right)$

Distensibility $(\mathrm{D})=2 \times(\mathrm{AASD}-\mathrm{AADD}) /[\mathrm{AADD} \times(\mathrm{SBP}-\mathrm{DBP})]\left(10^{-6} \mathrm{~cm}^{2} \mathrm{dyn}^{-1}\right)$

Strain $(\mathrm{S})=100 \times(\mathrm{AASD}-\mathrm{AADD}) / \mathrm{AADD}(\%)$

Stiffness index $(\mathrm{SI})=[\ln (\mathrm{SBP} / \mathrm{DBP})] /[(\mathrm{AASD}-\mathrm{AADD}) / \mathrm{AADD}]$

Peterson's elastic modulus $(E M)=A A D D \times(S B P-D B P) /\left(\right.$ AASD - AADD) $\left(10^{-6} \mathrm{~cm}^{-2} \mathrm{dyn}\right)$

\section{Intra-observer and Inter-observer variability}

The measurements of SBP, DBP, AASD, AADD, E/e and GLS were repeated in 30 randomly selected subjects after 1- month interval by the same physician (intra-observer variability) and another physician (inter-observer variability ). The elastic parameters of the ascending aorta: C, D, $\mathrm{S}, \mathrm{SI}$ and EM are calculated again to analyze intra-observer and inter-observer variability.

\section{Statistical Analysis}

Statistical analysis was performed using the SPSS version 19.0 software for Windows (SPSS, Chicago, Illinois). The Kolmogorov-Smirnov test was used to assess the normality of the quantitative variables, data was presented as mean \pm standard deviation (SD) and differences among the 3 groups were compared with one-way analysis of variance if normally distributed. Categorical variables were expressed as $n(\%)$ of the sample. Fischer's exact or $\chi^{2}$ tests were used in comparisons of categorical data between groups. A Pearson correlation analysis was performed to determine any possible relationship between $\mathrm{HbA}_{1 \mathrm{c}}$ and $\mathrm{LV}$ function and ascending aorta elasticity. Intra-class correlation coefficient (ICC) was used to evaluate intra- observer and inter-observer variability, an ICC $\geq 0.75$ means good reliability. The 2 - sided test was adopted, for all statistical tests with a $\mathrm{P}<0.05$ considered as statistically significant.

\section{Results}

\section{Baseline characteristics of study participants}

Baseline demographic and biochemical parameters of participants are shown in table 1. No statistical differences were found in age, gender, smoking history, SBP, DBP, PP, TCH, TG, HDL-C, LDL-C, height, weight and $\mathrm{BMI}$ among the 3 groups (all $\mathrm{P}>0.05$ ). And there were no statistical differences between controlled T2DM group and uncontrolled T2DM group in terms of the duration, complications and treatment of T2DM. Compared with controlled T2DM group, the FPG and $\mathrm{HbA}_{1 \mathrm{c}}$ were higher in uncontrolled T2DM group $(\mathrm{P}<0.05)$.

\section{Echocardiographic characteristics of participants}

Echocardiographic characteristics of the study groups are presented in Table 2. There were no significant differences in the LAD, IVSD, LVPWD, LVEDD, LVESD, LVEF, E, A and E/A among the 3 groups (all $P>0.05$ ). Compared with controls, GLS and $\overline{\mathrm{e}}$ decreased, $E / \overline{\mathrm{e}}$ increased in patients with T2DM $(P<0.05)$. Furthermore, there were significantly lower $G L S$ and $\overline{\mathrm{e}}$, and higher $E / \overline{\mathrm{e}}$ in uncontrolled T2DM group in comparison to controlled T2DM group $(\mathrm{P}<0.05)$.

\section{Elasticity parameters of ascending aorta}

The ascending aorta elastic parameters are shown in Table 3. All three groups did not differ in respect to ascending aorta inner diameters. Compared with controls, the $C, D$, and $S$ of the 
ascending aorta were lower and $\mathrm{SI}$ and $\mathrm{EM}$ were higher in T2DM patients (all $\mathrm{P}<0.05$ ). In uncontrolled T2DM group, the $\mathrm{C}, \mathrm{D}$, and $\mathrm{S}$ of the ascending aorta were lower and $\mathrm{SI}$ and $\mathrm{EM}$ were higher than those in controlled T2DM group (all $P<0.05$, Fig. 2).

\section{Correlation analysis between $\mathrm{HbA}_{1 \mathrm{c}}$ and $\mathrm{LV}$ function and ascending aorta elasticity}

A Pearson correlation analysis between $\mathrm{HbA}_{1 \mathrm{c}}$ and LV function and ascending aorta elasticity indicated that $\mathrm{HbA}_{1 \mathrm{c}}$ correlated well to LV GLS, $\mathrm{E} / \overline{\mathrm{e}}$ and elastic parameters of ascending aorta ( $\mathrm{P}$ $<0.05$, Table 4 ).

\section{Inter-observer and intra-observer variability}

Intra-observer and inter-observer variability for LV function and ascending aorta elasticity parameters are presented in Table 5. The ICCs for intra- and inter-observer variability were 0.871-0.965 and 0.874-0.957, respectively, which demonstrated that the measurement of LV function and ascending aorta elasticity parameters had a high consistent in inter-observer and intra-observer.

\section{Discussion}

The findings of our study indicate that the systolic and diastolic functions are impaired in T2DM patients, which is consistent with previous studies $[18,19]$. Furthermore, we also find that compared with the controlled T2DM group, the LV systolic and diastolic function are more severely impaired in the uncontrolled T2DM group. The cause of impaired LV function in diabetic patients may be that the presence of DCM. DCM was first proposed by Rubler et al. [20] in 1972, which was considered to be a change in the structure and function of the myocardial caused by diabetes. It is one of the main cardiac complications of diabetic patients and has a high incidence and great harm. DCM is closely related to the high incidence and high mortality of cardiovascular diseases in diabetic patients. About the mechanism of DCM, the current view is that: persistent hyperglycemia can not only activate oxidative stress, leading to increased production of reactive oxygen species and end-products of glycosylation which can induce apoptosis of cardiomyocytes and myocardial fibrosis [21-24], but also cause obstacles in anaerobic glycolysis and aerobic oxidation of glucose in myocardial tissue. Impaired sugar utilization in cardiomyocytes leads to increased fatty acid metabolism, and also lead to cardiomyocyte apoptosis [25]. In addition , overload of calcium in cardiomyocytes due to abnormal calcium regulation[26, 27], an activated renin-angiotensin-aldosterone system [28], altered substrate metabolism [29], and mitochondrial dysfunction [30] also involved in the mechanism of DCM.

Arterial elasticity is an important parameter indicating the state of the blood vessel walls [21]. Aortic stiffness reflects the mechanical tension and elasticity of the aortic wall. It is strongly associated with cardiovascular (CV) mortality and influenced by a variety of conditions. It has been reported that hypoelasticity of the ascending aorta was an independent predictor of all-cause death and CV events among individuals without overt CV disease [31]. So the early evaluation of ascending aorta elasticity has important clinical significance. Impaired elasticity of the ascending aorta in diabetic patients has been confirmed $[9,32]$. Toutouzas et al. have demonstrated that the impairment of aortic elasticity is associated with the duration of diabetes [33]. In the present study, patients with T2DM were further divided into two groups according to their $\mathrm{HbA}_{1 \mathrm{c}}$ levels. It was discovered that compared with controlled T2DM group, ascending aorta 
elastic properties were more impaired in uncontrolled T2DM group. It means that the damage to the elasticity of the ascending aorta is also related to the level of $\mathrm{HbA}_{1 \mathrm{c}}$. In patients with T2DM, sustained hyperglycemia lead to enhancement of oxidative stress, overproduction of reactive oxygen species, activation of Protein Kinase $\mathrm{C}$ and increased formation of advanced glycation end-products and chronic vascular inflammation, all these pathological processes eventually lead to vascular endothelial damage and the occurrence of aortic stiffness [34, 35].

Through the correlation analysis, we find that $\mathrm{HbA}_{1 c}$ correlate well to LV systolic function, LV diastolic function and ascending aorta elasticity. This means that poor blood glucose control in T2DM patients with the same disease duration will further worsen their cardiovascular function. Currently, diabetes mellitus is one of the most important health problems around the world [36]. To our knowledge, the importance of control blood glucose in patients who have not yet experienced complications has received little attention, leading to increased mortality and disability. Moreover, cardiovascular complications are the leading cause of morbidity and mortality in these patients $[37,38]$. So early detection of cardiovascular damage in diabetic mellitus patients, especially in patients with poor blood glucose control, is of great guiding value for early intervention measures, and can also raise people's awareness of the importance of blood glucose control.

\section{Research limitations}

Firstly, the sample size of our study was relatively small, so that further large-scale studies will be needed to validate our findings. Secondly, there is no further grouping study based on the level of $\mathrm{HbA}_{1 \mathrm{c}}$ among uncontrolled T2DM group to further confirm the effect of $\mathrm{HbA}_{1 \mathrm{c}}$ on LV function and ascending aorta elasticity. Thirdly, real-time three-dimensional speckle tracking imaging requires high image quality, and sometimes it is necessary to manually adjust the endocardium boundary to clearly display the endocardium, so it has a certain degree of subjectivity. Fourthly, due to the absence of a cut off value for ascending aorta elasticity parameters, we could not perform receiver operating characteristic curve analysis to identify an appropriate $\mathrm{HbA}_{1 c}$ level for hypoelasticity of the ascending aorta.

\section{Conclusion}

$\mathrm{HbA}_{1 \mathrm{c}}$ appears to be an important associated factor for LV function and ascending aorta elasticity in T2DM patients. The LV systolic and diastolic functions and ascending aorta elasticity are impaired in T2DM patients. Furthermore, in T2DM patients with uncontrolled blood glucose, their LV systolic and diastolic functions and ascending aorta elasticity suffer more severe damage. Early detection of LV dysfunction and decrease of ascending aorta elasticity in T2DM patients with echocardiography is of great significance for guiding early clinical intervention. Meanwhile, it can also improve the compliance of diabetics patients to control blood glucose.

\section{Abbreviations}

T2DM: type 2 diabetes mellitus; LV: left ventricular; $\mathrm{HbA}_{1 c}$ : glycosylated hemoglobin; LVEF: left ventricular ejection fraction; GLS: global longitudinal strain; E: early diastolic mitral inflow velocity; A: late diastolic mitral inflow velocity; $\overline{\mathrm{e}}$ : average mitral annular velocities; $\mathrm{C}$ : compliance; D: distensibility; S: strain; SI: stiffness index; EM: Peterson's elastic modulus; DCM: diabetic cardiomyopathy; BMI: body mass index, SBP: systolic blood pressure; DBP: diastolic 
blood pressure; PP: pulse pressure; TCH: total cholesterol; TG: triglycerides; HDL-C: high-density lipoprotein cholesterol; LDL-C: low-density lipoprotein cholesterol; FPG: fasting plasma glucose; LAD: left atrial diameter; IVSD: interventricular septal thickness in end-diastolic period; LVPWD: left ventricular posterior wall thickness in end-diastolic period; LVEDD: Left ventricular end-diastolic diameter; LVESD: Left ventricular end-systolic diameter; AADD: ascending aorta diastolic diameter; AASD: ascending aorta systolic diameter; SV: sinus of valsalva; STJ: sinotubular junction; TT: tubular tract; AoAr: aortic arch; ICC: intra-class correlation coefficient

\section{Acknowledgements}

Not applicable

\section{Authors' contributions}

X.T.S. and L.F. designed and carried out the study, data collection and analysis. X.T.S. wrote and revised the manuscript. X.S.T. and Z.N.Y. designed part of the experiments and acquired ultrasound images. X.T.S., L.F. and Y.F.R. performed the statistical analysis. All the authors have read and approved the manuscript.

\section{Funding}

The author(s) received no financial support for the research, author-ship, and/or publication of this article.

\section{Availability of data and materials}

The datasets generated and analyzed for this study are available from the corresponding author upon reasonable request.

\section{Ethics approval and consent to participate}

This study ([2019] KY023-01) was approved by the Human Subjects Committee of Changzhou No.2 People's Hospital. Verbal consents were obtained from all participants as instructed by the ethics committee.

\section{Consent for publication}

Not applicable.

\section{Competing interests}

The authors declare that they have no competing interests.

\section{References}

1. NCD Risk Factor Collaboration. Worldwide trends in diabetes since 1980: a pooled analysis of 751 population-based studies with 4.4 million participants. The Lancet. 2016;387(10027):1513-30.

2. Sarwar N, Gao P, Seshasai SR, Gobin R, Kaptoge S, Di Angelantonio E, Ingelsson E, Lawlor DA, Selvin E, Stampfer M, Stehouwer CD, Lewington S, Pennells L, Thompson A, Sattar N, White IR, Ray KK, Danesh J. Diabetes mellitus, fasting blood glucose concentration, and risk of vascular disease: a collaborative meta-analysis of 102 prospective studies. Lancet. 
2010;375(9733), 2215-22.

3. Bhatt DL, Eagle KA, Ohman EM, Hirsch AT, Goto S, Mahoney EM, Wilson PW, Alberts MJ, D'Agostino R, Liau CS, Mas JL, Röther J, Smith SC, Salette G, Contant CF, Massaro JM, Steg PG. Comparative determinants of 4-year cardiovascular event rates in stable outpatients at risk of or with atherothrombosis. JAMA. 2010;304(12):1350-7.

4. Boudina S, Abel ED. Diabetic cardiomyopathy revisited. Circulation. 2007;115(25):3213-23.

5. Aneja A, Tang WH, Bansilal S, Garcia MJ, Farkouh ME. Diabetic cardiomyopathy: insights into pathogenesis, diagnostic challenges, and therapeutic options. Am J Med. 2008;121(9):748-57.

6. von Bibra H, St John Sutton M. Diastolic dysfunction in diabetes and the metabolic syndrome: promising potential for diagnosis and prognosis. Diabetologia. 2010;53(6):1033-45.

7. Vinereanu D, Nicolaides E, Tweddel AC, Mädler CF, Holst B, Boden LE, Cinteza M, Rees AE, Fraser AG. Subclinical left ventricular dysfunction in asymptomatic patients with Type II diabetes mellitus, related to serum lipids and glycated haemoglobin. Clin Sci (lond). 2003;105(5):591-9.

8. Ernande L, Bergerot C, Rietzschel ER, De Buyzere ML, Thibault H, Pignonblanc PG, Croisille P,Ovize M, Groisne L, Moulin P, Gillebert TC, Derumeaux G. Diastolic dysfunction in patients with type 2 diabetes mellitus: is it really the first marker of diabetic cardiomyopathy? J Am Soc Echocardiogr. 2011;24(11):1268-75.e1.

9. Song XT, Fan L, Yan ZN, Rui YF. Evaluation of the Effect of Essential Hypertension on Elasticity of Ascending Aorta in Type 2 Diabetic Mellitus Patients by Echocardiography. Angiology, 2020; 71(6):536-43.

10. American Diabetes Association. Standards of medical care in diabetes-2010. Diabetes Care. 2010; 33 Suppl 1: S11-61.

11. Zhang $X$, Wei $X$, Liang Y, Liu M, Li C, Tang H. Differential changes of left ventricular myocardial deformation in diabetic patients with controlled and uncontrolled blood glucose: a three-dimensional speckle-tracking echocardiography-based study. J Am Soc Echocardiogr. 2013;26(5):499-506.

12. Jørgensen PG, Biering-Sørensen T, Mogelvang R, Fritz-Hansen T, Vilsbø\|l T, Rossing P, Jensen JS. Presence of micro- and macroalbuminuria and the association with cardiac mechanics in patients with type 2 diabetes. Eur Heart J Cardiovasc Imaging. 2018;19(9):1034-41.

13. Nagueh SF, Smiseth OA, Appleton CP, Byrd BF, Dokainish H, Edvardsen T, Flachskampf FA, Gillebert TC, Klein AL, Lancellotti P, Marino P, Oh JK, Popescu BA, Waggoner AD. Recommendations for the Evaluation of Left Ventricular Diastolic Function by Echocardiography: an Update from the American Society of Echocardiography and the European Association of Cardiovascular Imaging. J Am Soc Echocardiogr. 2016;29(4):277-314.

14. Nistri S, Grande-Allen J, Noale M, Basso C, Siviero P, Maggi S, Crepaldi G, Thiene G. Aortic elasticity and size in bicuspid aortic valve syndrome. Eur Heart J. 2008;29(4):472-9.

15. Nemes A, Geleijnse ML, Forster T, Soliman OI, Ten Cate FJ, Csanády M. Echocardiographic evaluation and clinical implications of aortic stiffness and coronary flow reserve and their relation. Clin Cardiol. 2008;31(7):304-9.

16. GREENFIELD JC, PATEL DJ. Relation between pressure and diameter in the ascending aorta of man. Circ Res. 1962;10:778-81. 
17. Ikonomidis I, Lekakis J, Stamatelopoulos K, Markomihelakis N, Kaklamanis PG, Mavrikakis M. Aortic elastic properties and left ventricular diastolic function in patients with Adamantiades-Behcet's disease. J Am Coll Cardiol. 2004;43(6):1075-81.

18. Bogdanović J, Ašanin $M$, Krljanac $G$, Lalić $N M$, Jotić $A$, Stanković $S$, Rajković $N$, Stošić $L$, Rasulić I, Milin J, Popović D, Bogdanović L, Lalić K. Impact of acute hyperglycemia on layer-specific left ventricular strain in asymptomatic diabetic patients: an analysis based on two-dimensional speckle tracking echocardiography. Cardiovasc Diabetol. 2019;18(1):68.

19. Haley JE, Zhiqian G, Philip KR, Nicolas ML, Thomas KR, Lawrence DM, Elaine UM. Reduction in myocardial strain is evident in adolescents and young adults with obesity and type 2 diabetes. Pediatr Diabetes. 2020;21(2):243-50.

20. Rubler S, Dlugash J, Yuceoglu YZ, Kumral T, Branwood AW, Grishman A. New type of cardiomyopathy associated with diabetic glomerulosclerosis. Am J Cardiol. 1972;30(6):595-602.

21. Poornima IG,Parikh P,Shannon RP. Diabetic cardiomyopathy: the search for a unifying hypothesis. Circ Res. 2006;98(5): 596-605.

22. Mizushige K,Yao L,Noma T,Kiyomoto H,Yu Y,Hosomi N,Ohmori K,Matsuo H. Alteration in left ventricular diastolic filling and accumulation of myocardial collagen at insulin-resistant prediabetic stage of a type II diabetic rat model. Circulation. 2000;101(8):899-907.

23. Cai L, Wang Y, Zhou G, Chen T, Song Y, Li X, Kang YJ. Attenuation by metallothionein of early cardiac cell death via suppression of mitochondrial oxidative stress results in a prevention of diabetic cardiomyopathy. J Am Coll Cardiol. 2006;48(8):1688-97.

24. Herrero P, Peterson LR, McGill JB, Matthew S, Lesniak D, Dence C, Gropler RJ. Increased myocardial fatty acid metabolism in patients with type 1 diabetes mellitus. J Am Coll Cardiol. 2006;47(3):598-604.

25. Golfman L, Dixon IM, Takeda N, Lukas A, Dakshinamurti K, Dhalla NS. Cardiac sarcolemmal $\mathrm{Na}(+)-\mathrm{Ca} 2+$ exchange and $\mathrm{Na}(+)-\mathrm{K}+$ ATPase activities and gene expression in alloxan-induced diabetes in rats. Mol Cell Biochem. 1998;188(1-2): 91-101.

26. Hattori Y, Matsuda N, Kimura J, Ishitani T, Tamada A, Gando S, Kemmotsu O, Kanno M. Diminished function and expression of the cardiac $\mathrm{Na}+-\mathrm{Ca} 2+$ exchanger in diabetic rats: implication in Ca2+ overload. J Physiol. 2000;527 Pt 1:85-94.

27. Zhou G, Li X, Hein DW, Xiang X, Marshall JP, Prabhu SD, Cai L. Metallothionein suppresses angiotensin II-induced nicotinamide adenine dinucleotide phosphate oxidase activation, nitrosative stress, apoptosis, and pathological remodeling in the diabetic heart. J Am Coll Cardiol. 2008;52(8):655-66.

28. Taegtmeyer $\mathrm{H}, \mathrm{McNulty} \mathrm{P}$, Young ME. Adaptation and maladaptation of the heart in diabetes: Part I: general concepts. Circulation. 2002;105(14):1727-33.

29. An D, Rodrigues B. Role of changes in cardiac metabolism in development of diabetic cardiomyopathy. Am J Physiol Heart Circ Physiol. 2006;291(4): H1489-506.

30. Anderson TJ. Arterial stiffness or endothelial dysfunction as a surrogate marker of vascular risk. Can J Cardiol. 2006;22 Suppl B: 72B-80B.

31. Redheuil A, Wu CO, Kachenoura N, Ohyama Y, Yan RT, Bertoni AG, Hundley GW, Duprez DA, Jacobs DR, Daniels LB, Darwin C, Sibley C, Bluemke DA, Lima JAC. Proximal aortic distensibility is an independent predictor of all-cause mortality and incident $\mathrm{CV}$ events: the MESA study. J Am Coll Cardiol. 2014;64(24):2619-29. 
32. Sciatti E, Vizzardi E, Castiello A, Valentini F, Bonadei I, Gelsomino S, Lorusso R, Metra M. The role of type 2 diabetes mellitus on hypertensive-related aortic stiffness. Echocardiography. 2018;35(6):798-803.

33. Toutouzas K, Stefanadis C, Tsiamis E, Vlachopoulos C, Tousoulis D, Tsioufis C, Toutouzas P. Aortic pressure-diameter relation in patients with non-insulin dependent diabetes mellitus: new insights. Diabetologia. 2000;43(8):1070-5.

34. Dong Y, Fernandes C, Liu Y, Wu Y, Wu H, Brophy ML, Deng L, Song K, Wen A, Wong S, Yan D, Towner $\mathrm{R}$, Chen $\mathrm{H}$. Role of endoplasmic reticulum stress signalling in diabetic endothelial dysfunction and atherosclerosis. Diab Vasc Dis Res. 2017;14(1):14 -23.

35. Katakami N. Mechanism of Development of Atherosclerosis and Cardiovascular Disease in Diabetes Mellitus. J Atheroscler Thromb. 2018;25(1):27-39.

36. Zimmet P, Alberti KG, Shaw J. Global and societal implications of the diabetes epidemic. Nature. 2001;414(6865):782-7.

37. Zheng Y, Ley SH, Hu FB. Global aetiology and epidemiology of type 2 diabetes mellitus and its complications. Nat Rev Endocrinol. 2018;14(2):88-98.

38. Low Wang CC, Hess CN, Hiatt WR, Goldfine AB. Clinical Update: Cardiovascular Disea se in Diabetes Mellitus: Atherosclerotic Cardiovascular Disease and Heart Failure in $T$ ype 2 Diabetes Mellitus-Mechanisms, Management, and Clinical Considerations. Circul ation. 2016;133(24):2459-502. 


\section{Figures}

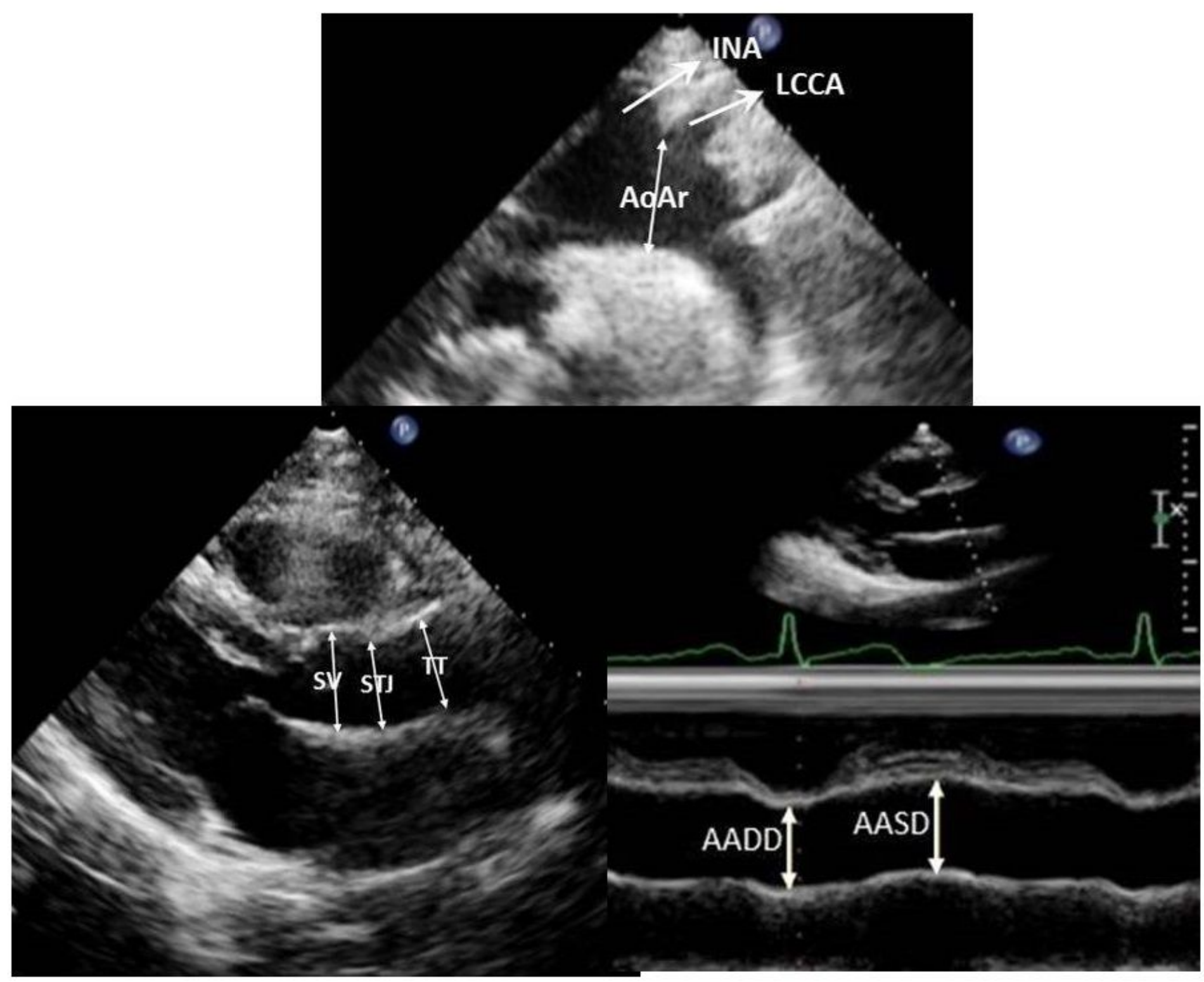

\section{Figure 1}

Measurement of aortic diameters in two-dimensional echocardiographic images. INA innominate artery, LCCA left common carotid artery, AoAr aortic arch, SV sinus of valsalva, STJ sinotubular junction, TT tubular tract, AADD ascending aorta diastolic diameter, AASD ascending aorta systolic diameter. 

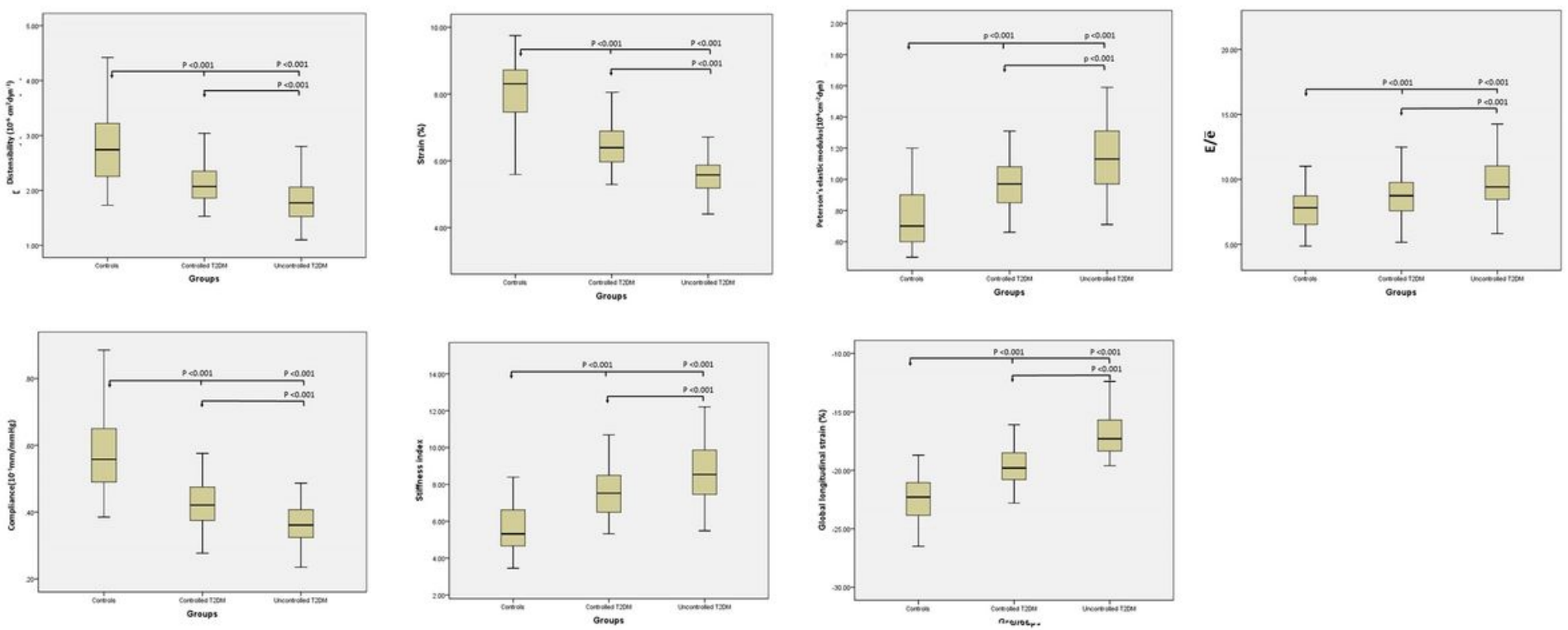

Figure 2

Differential changes of left ventricular function and ascending aorta elasticity among the three groups $C$ compliance, D distensibi-lity, S strain, SI stiffness index, EM Peterson's elastic modulus, GLS global longitudinal strain, E early diastolic mitral inflow velocity, $\mathrm{e} \otimes$ average mitral annular velocity, T2DM type 2 diabetes mellitus.

\section{Supplementary Files}

This is a list of supplementary files associated with this preprint. Click to download.

- table.docx 